\title{
Investigation of Cold Flow Properties of Waste Cooking Biodiesel
}

\author{
Gaurav Dwivedi and Mahendra Pal Sharma
}

\begin{abstract}
Waste cooking biodiesel has high potential as a new and renewable energy source in the future, as a substitution fuel for diesel and can be used in existing diesel engine without modification. But the major quality issue associated with biodiesel to use it as engine fuel is its poor cold flow property. The poor cold flow property results in gum formation and crystallization of fuel particles which lead to solidification of fuel lines and filters and creates the fuel starvation which will ultimately lead to starting problem in engine. The objective of this study to investigate and improve the cold flow properties of waste cooking biodiesel by blending and winterization. Blending was found to be more favourable for improvement in cold flow properties of biodiesel without any effect on yield. The result of experimental investigation shows that cloud point and pour point of waste cooking biodiesel $\left(\mathrm{WCB}_{100}\right)$ is improved from $14.5^{\circ} \mathrm{C}$ to $9^{\circ} \mathrm{C}$ and $13.7^{\circ} \mathrm{C}$ to $7.5^{\circ} \mathrm{C}$ respectively by three step winterization at the rate of $0.2^{\circ} \mathrm{C}$ at each step. The result also show that $20 \%$ ethanol blending lead to drastic improvement in cold flow properties of waste cooking biodiesel and makes it suitable to be used in cold climatic condition.
\end{abstract}

Index Terms-Biodiesel, cloud point, pour point, blending, ethanol.

\section{INTRODUCTION}

Self-reliance in energy is vital for overall economic development of developing countries like India. The search for alternative renewable, safe and non polluting energy sources has been accorded top priority in recent years. Further the uncertain supplies and frequent price hikes of fossil fuels in the international market are also posing serious economic threats followed by serious environmental consequence for developing countries [1]-[3]. Since petroleum diesel is heavily used for diesel engine based applications, therefore replacement of diesel by biodiesel obtained from the oil/fats seems to be only possibility of bio fuel production and utilization. Apart of edible/non edible seed oil producing plants, the waste cooking oil from cooking oils is the non agricultural production but the waste from kitchen. The plant based edible oil are corn, margarine, coconut, palm, olive, soybean, grape seed and canola, while the animal-based lipids, like butter, ghee and fish oil etc may be converted to biodiesel. Biodiesel is suitable renewable alternative liquid fuel being developed as substitute to diesel due to its biodegradability and desirable chemical characteristics [4], [5]. The major challenge behind the use of biodiesel as fuel is

Manuscript received July 8, 2014; revised May 12, 2015.

The authors are with the Biofuel Research Laboratory, Alternate Hydro Energy Centre, Indian Institute of Technology Roorkee, Roorkee, Uttarakhand 247667, India (tel.: 08126141004; e-mail: gdiitr2005@gmail.com). its poor cold flow properties (CFP) compared to petro diesel [6], [7]. Various methods can be used to improve the CFP of Waste cooking biodiesel (WCB) via blending, winterization and use of cold flow improvers. Poor CFP cause the plugging of fuel lines and filters and creates the fuel starvation which will ultimately lead to engine starting problem [8], [9]. Attempts are made in this paper to use winterization and ethanol as blending agent to improve the CFP of WCB.

\section{COLD FLOW PROPERTIES}

Crystallization of the saturated fatty acid during cold seasons causes fuel starvation and operability problems as solidified material clog fuel lines and filters. With decreasing temperature more solids form and material approaches the pour point, the lowest temperature at which it will cease to flow. It has been well established that the presence of higher amount of saturated components increases the cloud point and pour point of biodiesel utilization of additives that enhance the impact of crystal morphology; and blending with a fuel like kerosene which causes freezing point depression.

There is no single best way to assess low temperature performance, and the existing fuel standards (both U.S. and European) do not include explicit specifications for cold flow properties - for either conventional diesel or biodiesel. However, the fuel provider is generally required to give an indication of the cold flow properties by reporting the cloud point $(\mathrm{CP})$ of the fuel. A number of other laboratory tests are commonly used to define low temperature properties of biodiesel poor cold flow properties result from the presence of long chain, saturated FA esters present in biodiesel. These properties are defined as

\section{A. Cloud Point (CP)}

Cloud point $(\mathrm{CP})$ is the temperature at which wax form a cloudy appearance. It is measured as the temperature of first formation of wax as the fuel is cooled. The presence of solidified waxes thickens the oil and clogs fuel filters and injectors in engines. The wax also accumulates on cold surfaces and forms an emulsion with water. Therefore, cloud point indicates the tendency of the oil to plug filters or small orifices at cold operating temperatures.

\section{B. Pour Point (PP)}

Pour point (PP) is the lowest temperature at which the fuel becomes semi solid and loses its flow characteristics being no longer pump able; hence it is a measure of the fuel gelling point. The pour point is always lower than the cloud point.

\section{Cold Filter Plugging Point (CFPP)}

Cold filter plugging point (CFPP) is the lowest temperature, 
expressed in $1{ }^{\circ} \mathrm{C}$, at which a given volume of diesel type of fuel still passes through a standardized filtration device in a specified time when cooled under certain conditions. This gives an estimate for the lowest temperature that a fuel will give trouble free flow in certain fuel systems. This is important as in cold temperate countries; a high cold filter plugging point will clog up vehicle engines more easily [7].

\section{Standard Methods of Measurement of Cold Flow Property}

The following standard methods may used to measure the cold flow properties of biodiesel and its blends are shown in Table I.

TABLE I: StANDARD METHOD FOR MEASUREMENT OF COLD Flow

\begin{tabular}{lll}
\multicolumn{2}{c}{ PROPERTIES } \\
\hline \hline Test Name & Abbreviation & Test Method(s) \\
\hline Cloud point & CP & EN 23015, ASTM D2500, \\
& & ASTM \\
& & D5773 \\
Pour point & PP & ASTM D97, ASTM D5949 \\
Cold filter plugging & CFPP & EN 116, IP 309, ASTM \\
point & & D6371 \\
Low temp filterability & LTFT & ASTM D4539 \\
test & & \\
Wax appearance point & WAP & ASTM D3117 \\
Cold soak filterability & - & ASTM D7501 \\
\hline \hline
\end{tabular}

All three low temperature properties considered [cloud point $(\mathrm{CP})$, pour point (PP), and cold filter plugging point (CFPP)] show very similar patterns across the sets of 12 biodiesel types. In each case, biodiesel from palm oil and tallow show the poorest performance (highest temperature points), while biodiesel from rapeseed generally shows the best performance (lowest temperature points). Because of large seasonal and geographic temperature variability, neither the U.S. nor European biodiesel standards have firm specifications for these low temperature properties, though they are among the most important properties in determining the suitability of biodiesel fuels in-use. Poor cold flow properties result from the presence of long chain, saturated FA esters present in biodiesel. Saturated methyl esters longer than $\mathrm{C} 12$ significantly increase CP and pour point (PP). Feedstocks with highly saturated FA structures (such as palm oil and tallow) produce biodiesel fuels with poor cold flow properties; whereas feedstocks with highly unsaturated fatty acid structures (such as rapeseed and safflower oil) produce fuels having better performance.

Although the relationship between carbon chain length and low temperature properties is quite strong for pure FAME compounds, the effects appear more subtle when considering complex mixtures of FAME in actual biodiesel samples. Very similar results are observed when using PP and cold filter plugging point (CFPP) as indicators of low-temperature performance. In fact, the three metrics of CP, PP, and CFPP are highly correlated amongst themselves, suggesting that anyone could be used as an indicator of the others [10], [11].

In a homogenous mixture of many components with different melting points, crystallization is governed by the solubility of the components in the mixture. The low melting point components act as the solvent, while the high melting point components act as the solute. At any temperature below the melting point of the solute, crystallization will only occur if the solute is supersaturated in the solvent at that temperature. A solute is said to be supersaturated in a solvent when the solvent has dissolved more of the solute that it can hold at that particular temperature.

Thus, super-saturation depends on:

1) The temperature of the solution

2) The concentration of the solute in the solution

Three types of fatty acids can be found in any oil are:

1) Saturated fatty acids

2) Mono-unsaturated fatty acids

3) Poly-unsaturated fatty acid

Saturated fatty acids, due to their high degree of saturation, have higher melting points and temperatures of crystallization and in cold temperature they will crystallize before the mono-unsaturated and poly-unsaturated fatty acids. The melting points of the commonly encountered fatty acids and their corresponding methyl esters are given in Table I. Due to the high temperature of crystallization exhibited by the saturated fatty acids, biodiesel with high composition of saturated fatty acid esters exhibits worse cold flow and has higher cloud points indicating the crystallization of the esters of these saturated fatty acids.

Long carbon chain fatty acids also have a negative effect on the cold flow of biodiesel. Long carbon chain fatty acids have a higher temperature of crystallization as compared to the shorter carbon chain fatty acids and a high composition of esters of these fatty acids will worsen the cold flow of the biodiesel. The poor cold flow exhibited by peanut oil biodiesel is due to the presence of lingoceric and behenic acids, which have 22 and 24 carbon atoms without any double bond.

The presence of branches in the carbon chain of fatty acids gives the fatty acid a structure, which requires an increase in the thermodynamic force required for crystallization, and thus, decreasing the temperature of crystallization of the fatty acid. This in turn has a positive impact on the cold flow of the resultant biodiesel. In fact, the increase in the branching of resultant fatty acids by trans-esterification with branched chain alcohols has been employed as a means of improving the cold flow of biodiesel.

The following methods have been employed to improve the cold flow of biodiesel:

1) Blending with petroleum diesel

2) Trans-esterification with branched chain alcohol

3) Winterization

4) Use of chemical additives

5) Modification of fatty acid profiles of biodiesel

Blending biodiesel with petroleum diesel is the most widely employed method for the application of biodiesel, and the European committee for standardization has a limit of a maximum of $5 \%$ (by volume) of biodiesel blended in petroleum diesel and when blended with petroleum diesel in small quantities, the cold flow of the biodiesel is improved significantly. At low blend levels, petroleum diesel fuel, being miscible with biodiesels, dominates the effect of the high melting point of saturated esters [9].

\section{Biodiesel PRoduction Methodology}

Waste Cooking oil (WCO) was collected from IIT Roorkee 
hostel messes and it was filtered to remove all insoluble impurities from it followed by heating at $100^{\circ} \mathrm{C}$ for 10 minutes to remove all the moisture. Transesterification process was used for the conversion of oil into biodiesel. The fuel properties of WCO after refining was determined as per standard methods are reported in Table II.

TABLE II: PROPERTIES OF WASTE COOKING OII

\begin{tabular}{lll}
\multicolumn{2}{c}{ TABLE II: PROPERTIES OF WASTE COOKING OIL } \\
\hline \hline S.NO. & Properties & $\begin{array}{l}\text { Waste cooking } \\
\text { oil }\end{array}$ \\
\hline & & \\
1 & Net calorific value $(\mathrm{MJ} / \mathrm{kg})$ & 32.47 \\
2 & Flash point $\left({ }^{\circ} \mathrm{C}\right)$ & 236 \\
3 & Viscosity $(\mathrm{cSt}) @ 25^{\circ} \mathrm{C}$ & 47 \\
4 & FFA $(\%)$ & 0.9 \\
5 & Density $(\mathrm{kg} / \mathrm{m} 3) @ 25^{\circ} \mathrm{C}$ & 935 \\
\hline \hline
\end{tabular}

As per above table FFA contents is $0.9 \%$. Owing to low FFA content base catalyzed transesterification processes was adopted. For the biodiesel production from WCO mixture of methanol $(5 \% \mathrm{v} / \mathrm{v})$ and $\mathrm{KOH}(1 \% \mathrm{w} / \mathrm{w}$ of oil) was prepared and heated at $50^{\circ} \mathrm{C}$ then this hot mixture was mixed with WCO and stirred at $50^{\circ} \mathrm{C}$ for 2 hours later on mixture was allowed to settle down in separating funnel for overnight, at the end two layers were formed. The lower layer of glycerin was drained off by gravity, while the upper lighter layer was separated separately. A biodiesel yield of $97.05 \%$ was obtained was neutralized by $\mathrm{H}_{2} \mathrm{SO}_{4}$ and excess methanol was removed by vacuum distillation. The resulting biodiesel was washed thrice with hot water to remove excess impurities and dried over anhydrous $\mathrm{Na}_{2} \mathrm{SO}_{4}$.

\section{A. Fuel Properties}

The biodiesel samples were tested for physicochemical properties as per ASTM D-6751 and Indian IS 15607 specification and the properties are given in Table III which shows that although the WCB meets most of the specifications but according to Indian Climate, cannot be used in winter season.

TABLE III: PHYSICOCHEMICAL PROPERTIES OF WCB

\begin{tabular}{|c|c|c|c|c|}
\hline Property (unit) & $\begin{array}{c}\text { IS } \\
15607\end{array}$ & $\begin{array}{c}\text { IS } \\
15607 \\
\text { limit }\end{array}$ & WCB & Diesel \\
\hline Flash point $\left({ }^{\circ} \mathrm{C}\right)$ & IS 1448 & - & 170 & 60 \\
\hline $\begin{array}{c}\text { Viscosity at } 40^{\circ} \mathrm{C} \\
(\mathrm{cSt})\end{array}$ & IS 1448 & - & 4.15 & 2.1 \\
\hline $\begin{array}{c}\text { Water and } \\
\text { sediment (vol\%) }\end{array}$ & $\begin{array}{c}\text { D- } \\
2709\end{array}$ & $\begin{array}{l}\text { Max. } \\
0.05\end{array}$ & 0.05 & - \\
\hline $\mathrm{CP}\left({ }^{\circ} \mathrm{C}\right)$ & IS 1448 & - & 14.5 & 6 \\
\hline $\mathrm{PP}\left({ }^{\circ} \mathrm{C}\right)$ & IS 1448 & - & 13.7 & 5 \\
\hline
\end{tabular}

\section{EXPERIMENTAL INVESTIGATION OF COLD FLOW PROPERTY OF WASTE COOKING BIODIESEL}

Cloud point $(\mathrm{CP})$ and pour point (PP) were measured according to ASTM D-6751 test methods ASTM D2500, D97 respectively. The sample was cooled in a glass tube under prescribed conditions and inspected at intervals of $1^{\circ} \mathrm{C}$ until a cloud or haze appeared. This temperature was recorded as CP. In determination of PP, sample was cooled in a glass tube under prescribed conditions and inspected at intervals of $3^{\circ} \mathrm{C}$ until it is no longer moved when the place of surface was held vertical for 65 seconds; the PP was then taken as $3^{\circ} \mathrm{C}$ above the temperature of cessation of flow. All data was taken in triplicate and the mean of all is used. Subsequent analysis showed no statistically significant difference among the measurements. For winterization the sample was weighted and cooled to $0.2^{\circ} \mathrm{C}$ below its PP. The lower layer of biodiesel was solidified. The solid and liquid fractions were separated by using filter paper and pump. The weight of liquid and solid fractions were calibrated and the liquid portion was subjected to further test for calculating CP and PP as per ASTM D-6751. The CP and PP of liquid show the improvement. This process was repeated thrice to achieve three stage winterization of WCB.

\section{WINTERIZATION}

Winterization process was employed earlier to improve the quality of oils and fats, especially vegetable oils, not to become cloudy at low temperatures. It is a physical process of cooling a liquid fuel to undergo crystallization followed by fractionalization of fuel to remove its high melting components [9]. Extending this approach to biodiesel has been found to significantly reduce the $\mathrm{CP}$ and $\mathrm{PP}$ of the biodiesel. Biodiesel is cooled to $0.2^{\circ} \mathrm{C}$ below its $\mathrm{CP}$ and PP and any crystals formed are separated and reported. This process is repeated thrice until the crystals are no longer formed when the sample is held at that temperature for more than three hours. The solids formed are usually the crystals of the high melting point saturated fatty esters and the resultant liquid biodiesel is made to contain lower percentage of saturated fatty acids. The process of winterization results in the loss of biodiesel yield from $4.6 \%$ to $12.6 \%$ at each stage as shown in Table IV.

TABLE IV: WINTERIZATION OF WASTE COOKING BIODIESEL

\begin{tabular}{llllll}
\hline \hline Blend & \%Solid & \%liquid & $\%$ & $\mathrm{CP}$ & $\mathrm{PP}$ \\
& Mass $(\mathrm{g})$ & Mass $(\mathrm{g})$ & Yield & $\left({ }^{\circ} \mathrm{C}\right)$ & $\left({ }^{\circ} \mathrm{C}\right)$ \\
\hline WCB-100 & 0 & 50 & 100 & 14.5 & 13.7 \\
$\begin{array}{l}\text { WCB-100(1st } \\
\text { winterization) }\end{array}$ & 2.3 & 47.7 & 95.4 & 12 & 11 \\
$\begin{array}{l}\text { WCB-100(2nd } \\
\text { winterization) }\end{array}$ & 2.1 & 45.6 & 91.2 & 10.5 & 9.2 \\
$\begin{array}{l}\text { WCB-100(3rd } \\
\text { winterization) }\end{array}$ & 1.9 & 43.7 & 87.4 & 9 & 7.5 \\
\hline \hline
\end{tabular}

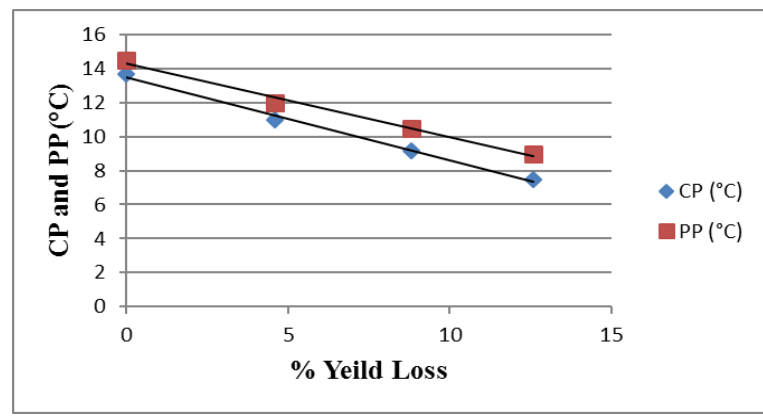

Fig. 1. Variation of CP and PP with \% yield loss.

Fig. 1 shows the variation of $\mathrm{CP}$ and $\mathrm{PP}$ with \% yield loss during the 3 step winterization process. The $R^{2}=0.990$ and 0.994 is obtained for CP and PP respectively which shows that the experiment results are hold good and significant for waste cooking biodiesel. Table III shows the improvement in 
$\mathrm{CP}$ and PP of WCB by $5.5^{\circ} \mathrm{C}$ and $6.2^{\circ} \mathrm{C}$ respectively but the biodiesel yield reduction of $12.6 \%$ reduction in three step winterization. During winterization at every step there is loss of saturated fatty acids which have an adverse effect on the cetane number of the biodiesel because of these saturated fatty acid, biodiesel have better ignition qualities and higher cetane numbers [9]. Moreover, the various steps required achieving a significant reduction in cloud point and the low yield translates into a higher production cost which impedes the widespread use of this particular method.

\section{BLENDING OF WASTE COOKING BIODIESEL WITH ETHANOL}

Waste cooking biodiesel (WCB) and ethanol were blended in weight percent 100:00 (WCB), 98:02, 95:05, 90:10, 85:15, and 80:20 (Ethanol). Fig. 2 shows that high CP and PP of PB was lowered after blending with the ethanol having low $\mathrm{CP}$ and PP. It is due low CP and PP value of ethanol.

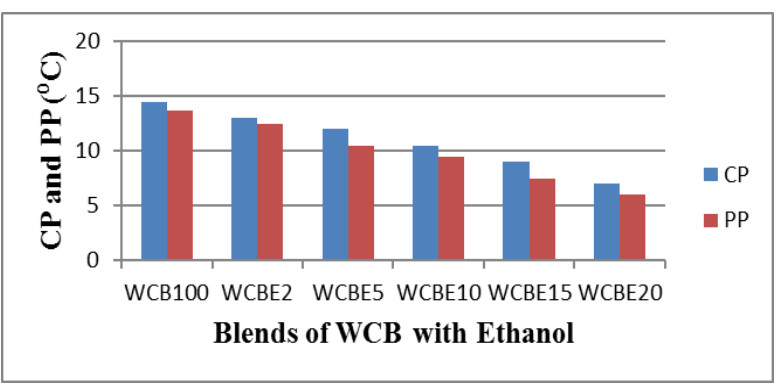

Fig. 2. Effect of ethanol blending with $\mathrm{WCB}$ on $\mathrm{CP}$ and PP.

The result of experiment shows the improvement in cloud point and pour point of waste cooking biodiesel blended with ethanol. The results show that as the biodiesel concentration percentage decreases the value of $\mathrm{CP}$ and $\mathrm{PP}$ is improved from $14.5^{\circ} \mathrm{C}$ to $7^{\circ} \mathrm{C}$ and $13.7^{\circ} \mathrm{C}$ to $6^{\circ} \mathrm{C}$ respectively. It shows that fuel $\mathrm{WCBE}_{20}$ can be recommended for cold climatic condition.

\section{CONCLUSION}

The experimental investigation shows that the cloud point and pour point of $\mathrm{WCB}$ is $14.5^{\circ} \mathrm{C}$ and pour point is $13.7^{\circ} \mathrm{C}$. The investigation includes the three step winterization of WCB. The effect of ethanol as blending agent for WCB is also investigated. The result of winterization shows the improvement in $\mathrm{CP}$ and $\mathrm{PP}$ of $\mathrm{WCB}$ by $5.5^{\circ} \mathrm{C}$ and $6.2^{\circ} \mathrm{C}$ respectively but the biodiesel yield reduction of $12.6 \%$ reduction in three steps while the ethanol remarkably improved the CP and PP of WCB. The CP and PP of WCB is improved from $14.5^{\circ} \mathrm{C}$ to $7^{\circ} \mathrm{C}$ and $13.7^{\circ} \mathrm{C}$ to $6^{\circ} \mathrm{C}$ respectively by blending with ethanol. Blending of biodiesel is simple but effective method to improve the low temperature flow properties, of biodiesel. The result shows that $\mathrm{WCBE}_{20}$ fuel can be recommended for cold climatic condition.

\section{ACKNOWLEDGEMENT}

The authors greatly acknowledge the financial support from MHRD, Govt. of India in the form of research scholarship to carry out this work.

\section{REFERENCES}

[1] L. Freire and L. Santos, "Influence of the synthesis process on the properties of flow and oxidative stability of biodiesel from Jatropha curcas biodiesel," Fuel, vol. 94, pp. 313-316, 2012.

[2] C. Echim, J. Maes, and W. D. Greyt, "Improvement of cold filter plugging point of biodiesel from alternative feedstocks," Fuel, vol. 93 , pp. 642-648, 2012.

[3] K. S. Hoekman and A. Broch. "Review of biodiesel composition, properties, and specifications," Renewable and Sustainable Energy Reviews, vol. 16, pp. 143-169, 2012.

[4] C. E. Zuleta and L. A. Rios, "Oxidative stability and cold flow behavior of palm, sacha-inchi, jatropha and castor oil biodiesel blends," Fuel Processing Technology, vol. 102, pp. 96-101, 2012.

[5] G. Dwivedi and M. P. Sharma. "Potential and limitation of straight vegetable oils as engine fuel - An Indian perspective," Renewable and Sustainable Energy Reviews, vol. 33, pp. 316-322, 2014.

[6] G. Dwivedi, M. P. Sharma, and S. Jain, "Pongamia as a source of biodiesel in India," Smart Grid and Renewable Energy, vol. 2, no. 3, pp. 184-189, 2011.

[7] G. Dwivedi and M. P. Sharma, "Impact analysis of biodiesel on engine performance - A review," Renewable and Sustainable Energy Reviews, vol. 15, pp. 4633-4641, 2011.

[8] S. H. Yoon and S. H. Park, "Experimental investigation on the fuel properties of biodiesel and its blends at various temperatures," Energy \& Fuels, vol. 22, pp. 652-656, 2008.

[9] O. Edith, R. B. Janius, and R. Yunus, "Factors affecting the cold flow behaviour of biodiesel and methods for improvement - A review," $J$. Sci. \& Technology, vol. 20, no. 1, pp. 1-14, 2012.

[10] S. K. Hoekmana, A. Brocha, C. Robbinsa, E. Cenicerosa, and M. Natarajanb, "Review of biodiesel composition, properties, and specifications," Renewable and Sustainable Energy Reviews, vol. 16, pp. 143-169, 2012.

[11] G. Dwivedi and M. P. Sharma, "Impact of cold flow properties of biodiesel on engine performance," Renewable and Sustainable Energy Reviews, vol. 31, pp. 650-656, 2014.

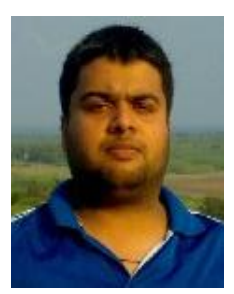

Gaurav Dwivedi was born in Silliguri, West Bengal, on August 17, 1984. He completed his B.Tech. degree in mechanical engineering from PTU and M.Tech. degree in alternate hydro energy system from IIT Roorkee, India. Currently he is pursuing his $\mathrm{PhD}$ degree in the field of renewable energy (bio-fuel) from IIT Roorkee, India. His areas of interest are IC engine, bio-fuel and thermodynamics.

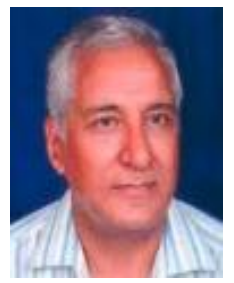

Mahendra Pal Sharma received his PhD degree from IIT Roorkee and currently is the head and an associate professor in AHEC, IIT Roorkee. His areas of interest are engine, bio-fuel and biomass, clean energy technology, water quality, GHG emission from reservoir. 